\title{
Characteristics and mechanisms of nickel adsorption on biochars produced from wheat straw pellets and rice husk
}

\author{
Zhengtao Shen $^{1}$ (i) - Yunhui Zhang ${ }^{1}$ - Oliver McMillan ${ }^{1} \cdot$ Fei Jin ${ }^{1} \cdot$ Abir Al-Tabbaa $^{1}$
}

Received: 4 November 2016 / Accepted: 16 March 2017 /Published online: 31 March 2017

(C) The Author(s) 2017. This article is published with open access at Springerlink.com

\begin{abstract}
The adsorption characteristics and mechanisms of $\mathrm{Ni}^{2+}$ on four-standard biochars produced from wheat straw pellets (WSP550, WSP700) and rice husk (RH550, RH700) at 550 and $700{ }^{\circ} \mathrm{C}$, respectively, were investigated. The kinetic results show that the adsorption of $\mathrm{Ni}^{2+}$ on the biochars reached an equilibrium within $5 \mathrm{~min}$. The increase of the solid to liquid ratio resulted in an increase of $\mathrm{Ni}^{2+}$ removal percentage but a decrease of the adsorbed amount of $\mathrm{Ni}^{2+}$ per weight unit of biochar. The $\mathrm{Ni}^{2+}$ removal percentage increased with the increasing of initial solution $\mathrm{pH}$ values at the range of $2-4$, was relatively constant at the $\mathrm{pH}$ range of $4-8$, and significantly increased to $\geq 98 \%$ at $\mathrm{pH} 9$ and stayed constantly at the $\mathrm{pH}$ range of 9-10. The calculated maximum adsorption capacities of $\mathrm{Ni}^{2+}$ for the biochars follow the order of WSP700 > WSP550 > RH700 > RH550. Both cation exchange capacity and $\mathrm{pH}$ of biochar can be a good indicator of the maximum adsorption capacity for $\mathrm{Ni}^{2+}$ showing a positively linear and exponential relationship, respectively. This study also suggests that a carefully controlled standardised production procedure can make it reliable to compare the adsorption capacities between different biochars and investigate the mechanisms involved.
\end{abstract}

Responsible editor: Guilherme L. Dotto

Electronic supplementary material The online version of this article (doi:10.1007/s11356-017-8847-2) contains supplementary material, which is available to authorized users.

Zhengtao Shen

ztshennju@gmail.com; zs281@cam.ac.uk

1 Geotechnical and Environmental Research Group, Department of Engineering, University of Cambridge, Cambridge CB2 1PZ, UK
Keywords Biochar $\cdot$ Standardised production $\cdot$ Adsorption studies · Adsorption capacity · Adsorption mechanisms . Nickel

\section{Introduction}

Biochar is produced by heating biomass (wood, grass, crop residues, manure and sewage sludge) under oxygen-limited conditions in a process called pyrolysis (Lehmann 2007; Sohi 2012). The incomplete carbonisation of the biomass during the pyrolysis process changes the properties of the feedstock, resulting in biochar with a porous structure, high surface area, high $\mathrm{pH}$, active functional groups and a graphitelike aromatic structure (Keiluweit et al. 2010; Manyà 2012; Ronsse et al. 2013; Xin et al. 2015). These properties result biochar with high adsorption capacities for heavy metals (Keiluweit et al. 2010; Beesley et al. 2011; Inyang et al. 2015). Therefore, the application of biochar to contaminated soils has gained increasing attention from scientists and engineers due to the predicted ability of biochar to immobilise heavy metal contaminants, in addition to its other benefits including low cost, carbon storage, greening and sustainability (Zhang et al. 2013; Sizmur et al. 2015; Shen et al. 2016).

Prior to field application in soil remediation, it is important to understand the adsorption characteristics and mechanisms of biochar for heavy metals in order to aid engineering design. Biochars with high adsorption capacities for heavy metals are preferred however site-specific factors such as heavy rainfall and changing soil $\mathrm{pH}$ should also be considered. A number of laboratory studies have been carried out to investigate the characteristics of heavy metal adsorption on biochar (Inyang et al. 2015); however, the biochar production conditions among different studies vary significantly, resulting in significant variations in the adsorption properties among biochars. It 
is not always possible to make relevant comparisons to adsorption capacities in the literature even for biochars derived from the same feedstock, as the production process may be differently controlled. It is therefore important to standardise the production process of biochar for laboratory adsorption studies so that the adsorption capacities of biochars can be reasonably compared across different studies; the adsorption mechanisms can be critically analysed; and the biochars which are most suitable for a specific contaminated site can be identified.

In addition, the characteristics of heavy metal adsorption on biochars produced from different feedstocks at different temperatures still need to be investigated as an addition to the existing biochar literature, to explore the adsorption mechanisms and aid the potential application of biochar in soil remediation. For instance, although wheat straw derived biochars exhibited a strong ability to remove methylene blue (Liu et al. 2012a) and to enhance crop yields (Qu et al. 2012), no existing studies have investigated the adsorption characteristics or mechanisms of $\mathrm{Ni}^{2+}, \mathrm{Cu}^{2+}$ or $\mathrm{Pb}^{2+}$ on wheat strawderived biochars to the best of the author's knowledge. Likewise, the adsorption characteristics of $\mathrm{Ni}^{2+}$ on biochar have not been studied.

In this study, four biochars, recommended by the UK Biochar Research Centre (UK Biochar Research Centre, 2016) as standard biochars, were produced from two plantbased feedstocks at two different temperatures at a standardised procedure. This study aims to (1) investigate the adsorption characteristics of heavy metals on these standard biochars, (2) identify the biochars which are suitable for future application to a contaminated site, and (3) understand the link between the physicochemical properties of these biochars and their adsorption capacities. $\mathrm{Ni}^{2+}$ was selected as the target metal ion in the adsorption studies as it exists in high concentrations at an existing contaminated site of interest to the authors (Shen et al. 2016). The carefully controlled production procedure of the biochars with high reproducibility (UK Biochar Research Centre, 2016) provides the reliability to compare the adsorption characteristics among the biochars and investigate the adsorption mechanisms involved.

\section{Materials and methods}

\section{Biochar}

The standard biochars were derived from wheat straw pellets (WSP) and rice husk (RH). Wheat and rice are two of the main crops across the world (Lal 2005), and a large number of their agricultural residues are generated every year, e.g. tonnes of unused wheat straw residues in North America (Alemdar and Sain 2008) and millions of tonnes of rice husks in China (Armesto et al. 2002). Therefore, the production of biochars from wheat straw and rice husk can both help deal with the agricultural wastes and aid the large-scale applications in soil remediation due to the high availability. WSP and RH were produced at 550 and $700{ }^{\circ} \mathrm{C}$, resulting in four biochars named WSP550, WSP700, RH550 and RH700. The pyrolysis process was carried out by the UKBRC at the University of Edinburgh, and production parameters were carefully controlled (UKBRC 2016), resulting in high reproducibility of the standard biochars. Upon receipt, the biochars were oven dried at $60^{\circ} \mathrm{C}$ for $48 \mathrm{~h}$ and sieved to a particle size of less than $0.15 \mathrm{~mm}$ for further analysis. The cation exchange capacity (CEC) of biochar was determined by a compulsive exchange method based on (Gillman and Sumpter 1986). The surface morphology of the biochar was examined by a scanning electron microscopy (SEM) at $15 \mathrm{kV}$ after coated with gold. The infrared spectrum of biochar was obtained using a PerkinElmer Spectrum 100 Fourier transform infrared spectroscopy (FT-IR) spectrometer by taking 16 scans from 4000 to $450 \mathrm{~cm}^{-1}$ with a resolution of $1 \mathrm{~cm}^{-1}$. Other physicochemical properties of biochar were tested by the UKBRC and can be found from (UK Biochar Research Centre, 2016).

The physicochemical properties of the biochars are shown in Table 1. The physicochemical properties of the biochars are significantly affected by the feedstock and production temperature. For instance, the biochars consist primarily of carbon and ash, but WSP-derived biochars contains significantly higher carbon contents (68.26-69.04\%) compared with RH (47.32-48.69\%) and lower ash contents (21.25-23.82\% and $47.93 \%$ for WSP- and RH-derived biochars, respectively). Increasing the production temperature from 550 to $700{ }^{\circ} \mathrm{C}$

Table 1 Physicochemical properties of the biochars

\begin{tabular}{crrrr}
\hline & WSP550 & WSP700 & RH550 & RH700 \\
\hline C (\%) & 68.26 & 69.04 & 48.69 & 47.32 \\
H (\%) & 2.10 & 1.18 & 1.24 & 0.63 \\
O (\%) & 6.92 & 5.30 & 2.47 & 2.06 \\
N (\%) & 1.39 & 1.32 & 1.04 & 0.85 \\
P (\%) & 0.14 & 0.25 & 0.10 & 0.16 \\
VM (\%) & 10.55 & 7.38 & 7.48 & 4.99 \\
H:C & 0.37 & 0.20 & 0.28 & 0.16 \\
O:C & 0.08 & 0.06 & 0.04 & 0.03 \\
Total ash (\%) & 21.25 & 23.82 & 47.93 & 47.93 \\
pH & 9.94 & 10.03 & 9.71 & 9.81 \\
Surface area (m $/ \mathrm{g})$ & 26.40 & 23.20 & 20.10 & 42.00 \\
CEC (cmol/kg) & 7.15 & 12.50 & 4.22 & 5.36 \\
K (\%) & 1.56 & 1.47 & 0.39 & 0.62 \\
Ni (mg/kg) & 1.00 & 2.50 & 3.00 & 2.71 \\
\hline
\end{tabular}

The standard deviations (SD) for CEC were within 0.10-0.23; the SD for other properties can be found from (UKBRC 2016)

$V M$ volatile matter, $C E C$ cation exchange capacity 
resulted in a slight decrease of surface area from 26.40 to $23.20 \mathrm{~m}^{2} / \mathrm{g}$ for WSP-derived biochars while a significant increase from 21.10 to $42.00 \mathrm{~m}^{2} / \mathrm{g}$ for RH-derived biochars. WSP-derived biochars showed significantly higher $\mathrm{H}, \mathrm{O}, \mathrm{N}$ and $\mathrm{P}$ contents, VM content, $\mathrm{H}: \mathrm{C}$ and $\mathrm{O}: \mathrm{C}$ values, $\mathrm{pH}$ and $\mathrm{CEC}$, compared with $\mathrm{RH}$ at the same production temperature. For the same feedstock, increasing production temperature decomposes the cellulose, hemicellulose and lignin in the raw materials (Keiluweit et al. 2010), leading to lower H, O and $\mathrm{N}$ contents, $\mathrm{VM}$ content and $\mathrm{H}: \mathrm{C}$ and $\mathrm{O}: \mathrm{C}$ values, but higher $\mathrm{pH}$ and $\mathrm{CEC}$ which are probably due to the accompanied generation of alkaline minerals (Dodson 2011).

\section{Adsorption studies}

Batch adsorption experiments were carried out in polyethylene tubes in a temperature-controlled lab $\left(20 \pm 1{ }^{\circ} \mathrm{C}\right)$. Solutions of $0.01,0.1$ and $1 \mathrm{M} \mathrm{HNO}_{3}$ and $0.01,0.1$ and $1 \mathrm{M}$ $\mathrm{NaOH}$ were used to adjust the initial $\mathrm{pH}$ of the solutions where required. For each experiment, the biochar-solution mixture was filtered with a $0.45-\mu \mathrm{m}$ filter after the designated shaking time. The $\mathrm{Ni}^{2+}$ concentration in the collected filtrate was measured by inductively coupled plasma/optical emission spectrometry (ICP-OES) (Perkin-Elmer, 7000DV).

\section{Kinetics}

In order to assess the adsorption kinetics of the biochars, a certain amount of biochar $(0.1 \mathrm{~g})$ was added to $20 \mathrm{~mL}$ solutions of $5 \mathrm{mM}$ $\mathrm{Ni}\left(\mathrm{NO}_{3}\right)_{2}(\mathrm{pH}=5)$ containing $0.01 \mathrm{M} \mathrm{NaNO}_{3}$ (for a stable ionic strength of the solution). The mixture was shaken at $200 \mathrm{rpm}$ for $5,10,20$ or 30 min or $1,2,3,6,12$ or $24 \mathrm{~h}$. These tests confirmed that the equilibrium adsorption time for all biochars was no longer than $5 \mathrm{~min}$, and longer adsorption time does not affect the equilibrium. Therefore, a reaction time of $24 \mathrm{~h}$ was used in the following adsorption studies, which is the same as the previous study (Shen et al. 2015).

\section{Influence of solid to liquid ratio}

In order to assess the effects of solid to liquid ratio on $\mathrm{Ni}^{2+}$ adsorption, a measured amount of biochar $(0.1,0.2,0.3,0.4$, $0.5,0.6,0.7,0.8,0.9$ or $1 \mathrm{~g}$ ) was added to $20 \mathrm{~mL}$ of $5 \mathrm{mM} \mathrm{Ni}$ $\left(\mathrm{NO}_{3}\right)_{2}$ solutions $(\mathrm{pH}=5)$ containing $0.01 \mathrm{M} \mathrm{NaNO}_{3}$. The mixture was shaken at $200 \mathrm{rpm}$ for $24 \mathrm{~h}$ to reach equilibrium.

\section{Influence of $p H$}

In order to assess the effect of initial solution $\mathrm{pH}$ on $\mathrm{Ni}^{2+}$ adsorption, a certain amount of biochar $(0.1 \mathrm{~g})$ was added to $20 \mathrm{~mL}$ of $5 \mathrm{mM} \mathrm{Ni}\left(\mathrm{NO}_{3}\right)_{2}$ solution (containing $0.01 \mathrm{M}$ $\mathrm{NaNO}_{3}$ ). The initial $\mathrm{pH}$ of each solution (before biochar addition) was adjusted to $2,3,4,5,6,7,8,9$ or 10 . The mixture was shaken at $200 \mathrm{rpm}$ for $24 \mathrm{~h}$ to reach equilibrium. The equilibrium $\mathrm{pH}$ of each solution was measured, and the point of zero charge $\left(\mathrm{pH}_{\mathrm{pzc}}\right)$ of each biochar was obtained from a plot of initial solution $\mathrm{pH}$ against equilibrium solution $\mathrm{pH}$, based on Mohan et al. (2014). In order to separate the precipitated $\mathrm{Ni}(\mathrm{OH})_{2}$ due to its solubility at different $\mathrm{pHs}$, the fractions of $\mathrm{Ni}^{2+}$ removal caused by this effect were calculated using Visual MINTEQ 3.1 based on the initial concentrations of $\mathrm{Ni}^{2+}, \mathrm{Na}^{+}$and $\mathrm{NO}_{3}{ }^{-}$and the equilibrium solution $\mathrm{pH}$.

\section{Equilibrium study}

In order to construct an isotherm for each biochar, a certain amount of biochar $(0.1 \mathrm{~g})$ was added to $20 \mathrm{~mL}$ solutions $(\mathrm{pH}=5)$ containing different $\mathrm{Ni}^{2+}$ concentrations $(0.1,0.2$, $0.3,0.5,1,2,3$ or $5 \mathrm{mM}$ ) and $0.01 \mathrm{M} \mathrm{NaNO}_{3}$. The mixture was shaken at $200 \mathrm{rpm}$ for $24 \mathrm{~h}$ to reach equilibrium.

\section{Calculation}

The adsorbed amount of $\mathrm{Ni}^{2+}$ on biochar was calculated using Eq. (1).

$q_{\mathrm{e}}=\frac{\left(C_{0}-C_{\mathrm{e}}\right) V}{W}$

where $q_{e}$ is the amount ( $\mathrm{mmol} / \mathrm{g}$ ) of $\mathrm{Ni}^{2+}$ adsorbed on biochar. $C_{0}(\mathrm{mM})$ and $C_{\mathrm{e}}(\mathrm{mM})$ are the initial and final Ni concentrations in solutions. $V$ is the solution volume $(\mathrm{L}) . W$ is the biochar weight $(\mathrm{g})$.

For the influence of solid to liquid ratio and initial solution $\mathrm{pH}$ on adsorption, the removal percentage of $\mathrm{Ni}^{2+}$ in solution was calculated using Eq. (2). The adsorbed amount of $\mathrm{Ni}^{2+}$ per weight unit of biochar was calculated using Eq. (1).

$P_{\mathrm{R}}=\frac{C_{\mathrm{e}}-C_{0}}{C_{0}}$

where $P_{\mathrm{R}}$ is the removal percentage of $\mathrm{Ni}^{2+} . C_{0}(\mathrm{mM})$ and $C_{\mathrm{e}}$ $(\mathrm{mM})$ are as per Eq. (1).

For the equilibrium study, the experimental data were fitted using Langmuir and Freundlich isotherm models, which are typically used to describe the adsorption isotherms and predict the mechanisms (Foo and Hameed 2010). The Langmuir model is expressed as Eq. (3).

$q_{\mathrm{e}}=\frac{Q_{\mathrm{max}} \mathrm{b} C_{\mathrm{e}}}{1+b C_{\mathrm{e}}}$

where $q_{\mathrm{e}}$ and $C_{\mathrm{e}}$ are defined as per Eq. (1). $\mathrm{Q}_{\max }(\mathrm{mmol} / \mathrm{g})$ and $b(\mathrm{~L} / \mathrm{mmol})$ are the Langmuir constants representing the maximum adsorption capacity and rate of adsorption. 


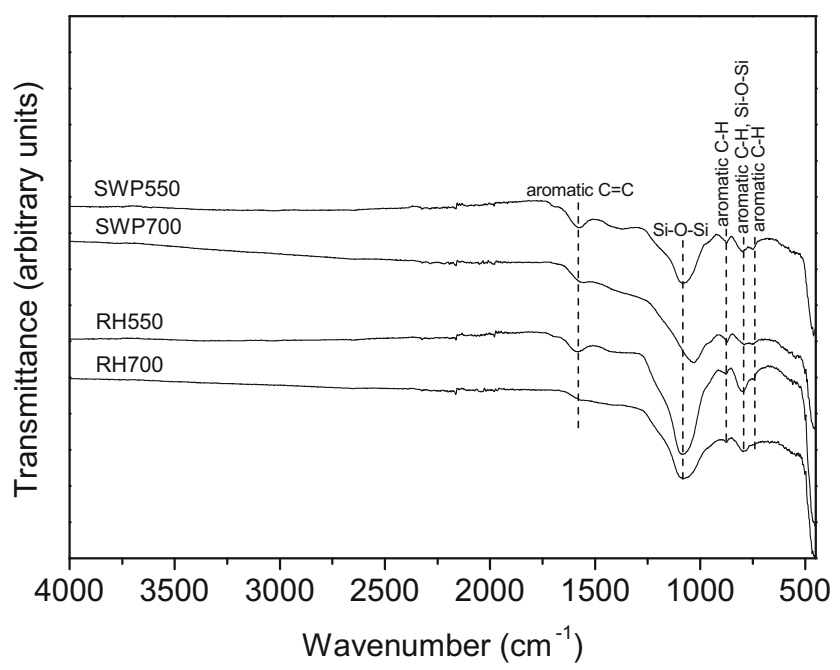

Fig. 1 FT-IR spectra of the biochars

The Freundlich model is expressed as Eq. (4).

$q_{\mathrm{e}}=K_{\mathrm{F}} C_{\mathrm{e}}^{1 / n}$

where $q_{\mathrm{e}}$ and $C_{\mathrm{e}}$ are defined as per Eq. (1). $K_{\mathrm{F}}(\mathrm{mmol} / \mathrm{g})$ and $n$ are Freundlich constants. $K_{\mathrm{F}}$ is the adsorption capacity of the adsorbent, and $n$ indicates the degree of favourable of the adsorption process. $1 / n$ ranges between 0 and 1 and is a measure of adsorption intensity or surface heterogeneity. A lower $1 / n$ value indicates a greater degree of heterogeneity on the biochar surface.

All experiments were conducted in duplicates. The means and standard deviations were calculated and presented for each experiment. Regression was used to evaluate the fitness of the prediction models to the experimental data in this study using Origin 8.5 . The suitability of the model fitting was assessed using $R^{2}$ values and Akaike information criterion (AIC) values.

\section{Results and discussion}

\section{FT-IR spectra and SEM images}

The FT-IR spectra of the biochars, as shown in Fig. 1, indicate the presence of aromatic $\mathrm{C}=\mathrm{C}$ stretching $\left(1575-1585 \mathrm{~cm}^{-1}\right)$ (Keiluweit et al. 2010), Si-O-Si asymmetric vibration (1035-1080 and $800 \mathrm{~cm}^{-1}$ ) (Liu et al. 2012a; Liu et al. 2012b) and aromatic C-H bending (750, 800 and $\left.875 \mathrm{~cm}^{-1}\right)$ (Keiluweit et al. 2010). The stronger Si-O-Si peak of RHderived biochars compared with that of WSP suggests that RH-derived biochars may have more $\mathrm{SiO}_{2}$ contents, which is also reflected by their higher ash contents (Table 1). For the same feedstock, a higher production temperature resulted in a weaker peak for aromatic $\mathrm{C}=\mathrm{C}$ and $\mathrm{C}-\mathrm{H}$. This is due to the condensation of aromatic structure at higher temperatures
(Keiluweit et al. 2010). WSP and RH primarily contain cellulose and semi-cellulose (Keiluweit et al. 2010); however, no peaks associated with $\mathrm{O}$-containing functional groups $(\mathrm{C}=\mathrm{O}$, $\mathrm{C}-\mathrm{O}, \mathrm{O}-\mathrm{H}$ ) or aliphatic $\mathrm{C}-\mathrm{H}$ was observed, indicating a high degree of aromatization of the feedstocks during biochar production (Keiluweit et al. 2010). The SEM images of the biochars (Fig. 2) show the active porous structures on all biochar surfaces. WSP700 exhibited a heterogeneous distribution of pore diameters from $<1$ to $\sim 20 \mathrm{um}$. In contrast, RH700 showed relatively homogeneous distribution of macro pores with diameters of $\sim 10-20 \mathrm{um}$.

\section{Kinetics}

The adsorption profiles of $\mathrm{Ni}^{2+}$ to the biochars over time are shown in Fig. 3. The adsorption of $\mathrm{Ni}^{2+}$ on all biochars reached equilibriums within $5 \mathrm{~min}$. WSP700 exhibited the highest adsorption capacity $(\sim 0.39 \mathrm{mmol} / \mathrm{g})$ at the initial $\mathrm{Ni}^{2+}$ concentration of $5 \mathrm{mM}$, followed by WSP500 $(\sim 0.24 \mathrm{mmol} / \mathrm{g})$, RH700 $(\sim 0.19 \mathrm{mmol} / \mathrm{g})$ and RH550 ( $0.13 \mathrm{mmol} / \mathrm{g})$. At the initial $\mathrm{Ni}^{2+}$ concentration of $5 \mathrm{mM}$, WSP-derived biochars exhibited higher adsorption capacities than RH. For the same feedstock, higher production temperature results in a higher adsorption capacity.

The rapid reaction in this study coincides with the findings of Saleh et al. (2016) and Tran et al. (2016). Saleh et al. (2016) used sunflower seed husk biochar $(\leq 0.5 \mathrm{~mm})$ to adsorb $\mathrm{Cu}^{2+}$ (Solid to liquid ratio 1:200 $\mathrm{g} / \mathrm{mL}$, initial $\mathrm{Cu}^{2+}$ concentration $1.5 \mathrm{mM}$ ) in aqueous solutions and observed that more than $95 \%$ of the totally adsorbed $\mathrm{Cu}^{2+}$ at equilibrium was adsorbed on the biochar within $5 \mathrm{~min}$. Similarly, Tran et al. (2016) used orange peel-derived biochar $(\leq 0.71 \mathrm{~mm})$ to adsorb $\mathrm{Cd}^{2+}$ (solid to liquid ratio $2 \mathrm{~g} / \mathrm{L}$, initial $\mathrm{Cd}^{2+}$ concentration $100 \mathrm{mg} / \mathrm{L}$ ) and found that approximately $80.6-96.9 \%$ of the totally adsorbed $\mathrm{Cd}^{2+}$ was removed within $1 \mathrm{~min}$. The ability of the biochars to rapidly remove $\mathrm{Ni}^{2+}$ from solution and no appearance of desorption within $24 \mathrm{~h}$ suggests that there is a potential for the biochars to rapidly treat heavy metals in soil and water. It is of note that the relatively small particle sizes $(\leq 0.15 \mathrm{~mm})$ may also contribute to this rapid reaction, as Rees et al. (2014) found that short-term adsorption of heavy metals $\left(\mathrm{Cu}^{2+}\right.$, $\mathrm{Cd}^{2+}$ and $\mathrm{Ni}^{2+}$ ) is highly dependent on intra-particle diffusion, with fine biochar particles $(\leq 0.2 \mathrm{~mm})$ adsorbing heavy metals significantly faster than coarse particles $(0.2-2 \mathrm{~mm})$. As the findings (the rapid adsorption of $\mathrm{Ni}^{2+}$ on all biochars) from the kinetic study are significant and the initial stage where the $q_{\mathrm{e}}$ commonly increases with time was not observed, the kinetic data were not fitted using kinetic models for a further analysis.

\section{Influence of solid to liquid ratio on $\mathrm{Ni}^{2+}$ adsorption}

The influences of solid to liquid ratio on $\mathrm{Ni}^{2+}$ removal percentage and the adsorbed amount of $\mathrm{Ni}^{2+}$ per weight unit of 
Fig. 2 SEM images of the biochars

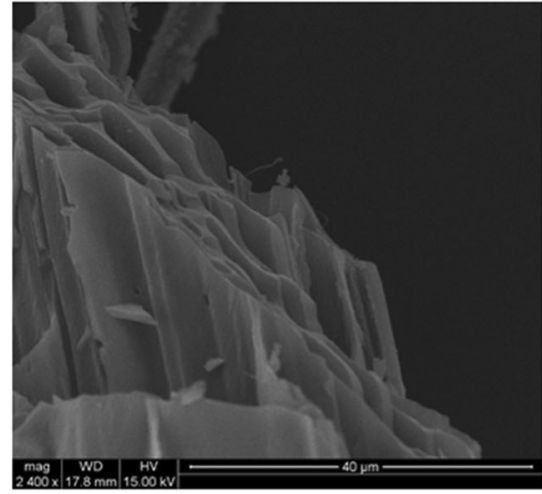

WSP550

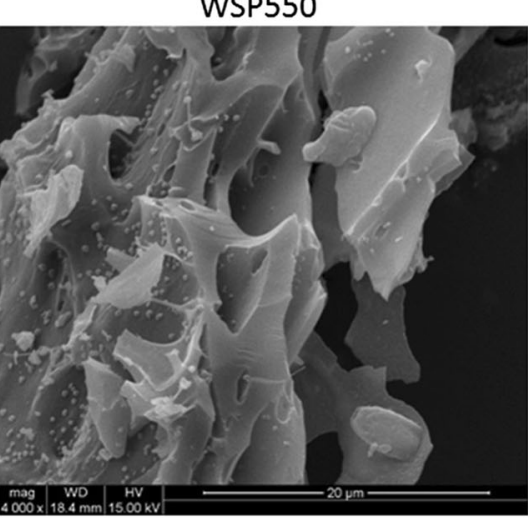

RH550

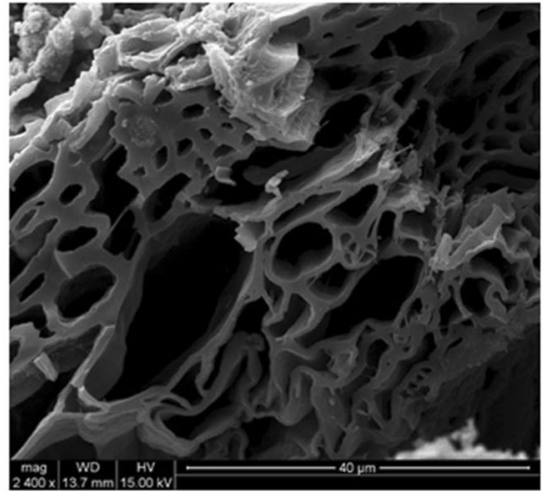

WSP700

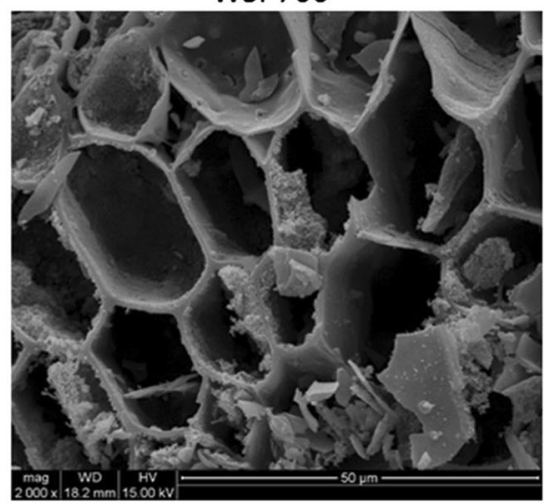

RH700 biochar are shown in Fig. 4. The $\mathrm{Ni}^{2+}$ removal percentage of WSP700 increased rapidly from 39.30 to $99.45 \%$ as the solid to liquid ration increased from 5 to $15 \mathrm{~g} / \mathrm{L}$, and stayed constantly when the solid to liquid ratio continued to increase to $50 \mathrm{~g} / \mathrm{L}$. The $\mathrm{Ni}^{2+}$ removal percentage of WSP550 and RH700 increased from 23.80 and $18.56 \%$, respectively, at $5 \mathrm{~g} / \mathrm{L}$ to close to $\geq 99 \%$ at $40 \mathrm{~g} / \mathrm{L}$ and further stayed constantly. The $\mathrm{Ni}^{2+}$ removal percentage of RH550 increased with the increasing of solid to liquid ratio, however, did not complete removal (maximum of $87.54 \%$ ) in the experimental range of $5-50 \mathrm{~g} / \mathrm{L}$,

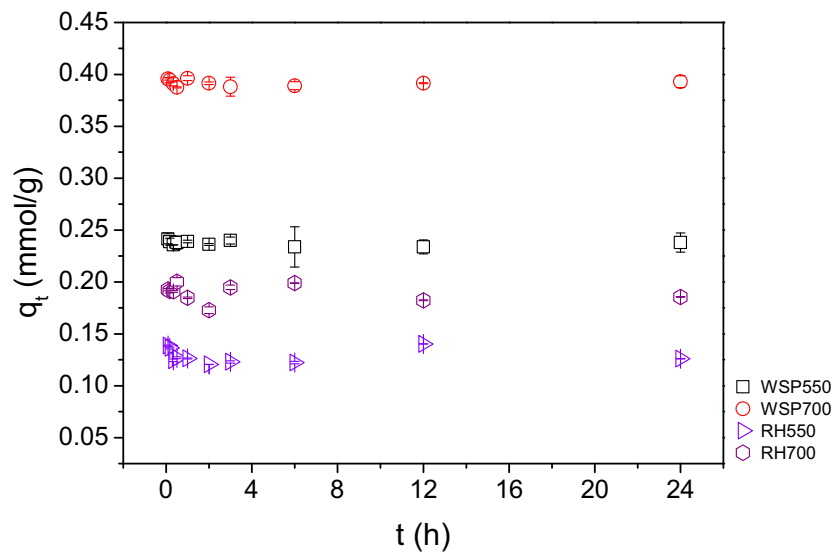

Fig. 3 Kinetics of $\mathrm{Ni}^{2+}$ adsorption on biochars $\left(q_{\mathrm{t}}\right.$-adsorbed amount at time $\mathrm{t}$, t- time) ( $0.1 \mathrm{~g}$ biochar in $20 \mathrm{~mL}$ solution $\left(0.01 \mathrm{M} \mathrm{NaNO}_{3}\right)$, initial $\mathrm{Ni}^{2+}$ concentration $5 \mathrm{mM}$; reaction temperature $20{ }^{\circ} \mathrm{C}$; initial solution $\mathrm{pH}$ 5) due to its low adsorption capacity compared with other biochars, as indicated in Fig. 3. WSP700 completed $\mathrm{Ni}^{2+}$ removal ( $\geq 99 \%)$ using the least solid amount $(0.3 \mathrm{~g})$ whereas that for WSP550 and RH700 was much higher (0.8 g), which is also in line with their adsorption capacities observed from Fig. 3. The adsorbed amount of $\mathrm{Ni}^{2+}$ per weight unit of biochar decreased as solid to liquid ratio increased from 5 to $50 \mathrm{~g} / \mathrm{L}$ for all biochars, which is similar to the findings from Meng et al. (2014) and Shen et al. (2015).

\section{Influence of solution $\mathrm{pH}$ on $\mathrm{Ni}^{2+}$ adsorption}

Figure 5 shows the influences of initial solution $\mathrm{pH}$ on $\mathrm{Ni}^{2+}$ removal percentage and the equilibrium solution $\mathrm{pH}$, as well as the fractions of $\mathrm{Ni}^{2+}$ removal due to precipitation calculated from the $\mathrm{Ni}(\mathrm{OH})_{2}$ solubility data using MINTEQ database. The $\mathrm{pH}_{\mathrm{pzc}}$ values of all biochars, obtained from Fig. 5, are found to be within the range of 7.3-7.8, indicating that the surface of the biochars may be positively charged in slightly alkaline $\left(7<\mathrm{pH}<\mathrm{pH}_{\mathrm{pzc}}\right)$ and acidic environment, which may not aid their adsorption towards positively charged heavy metal ions due to electrostatic repulsion (Gao et al. 2013). However, on the other hand, the high $\mathrm{pH}_{\mathrm{pzc}}$ and $\mathrm{pH}$ values suggest the strong alkalinity of the biochars which will aid their adsorption for heavy metals through surface precipitation (Inyang et al. 2015). 

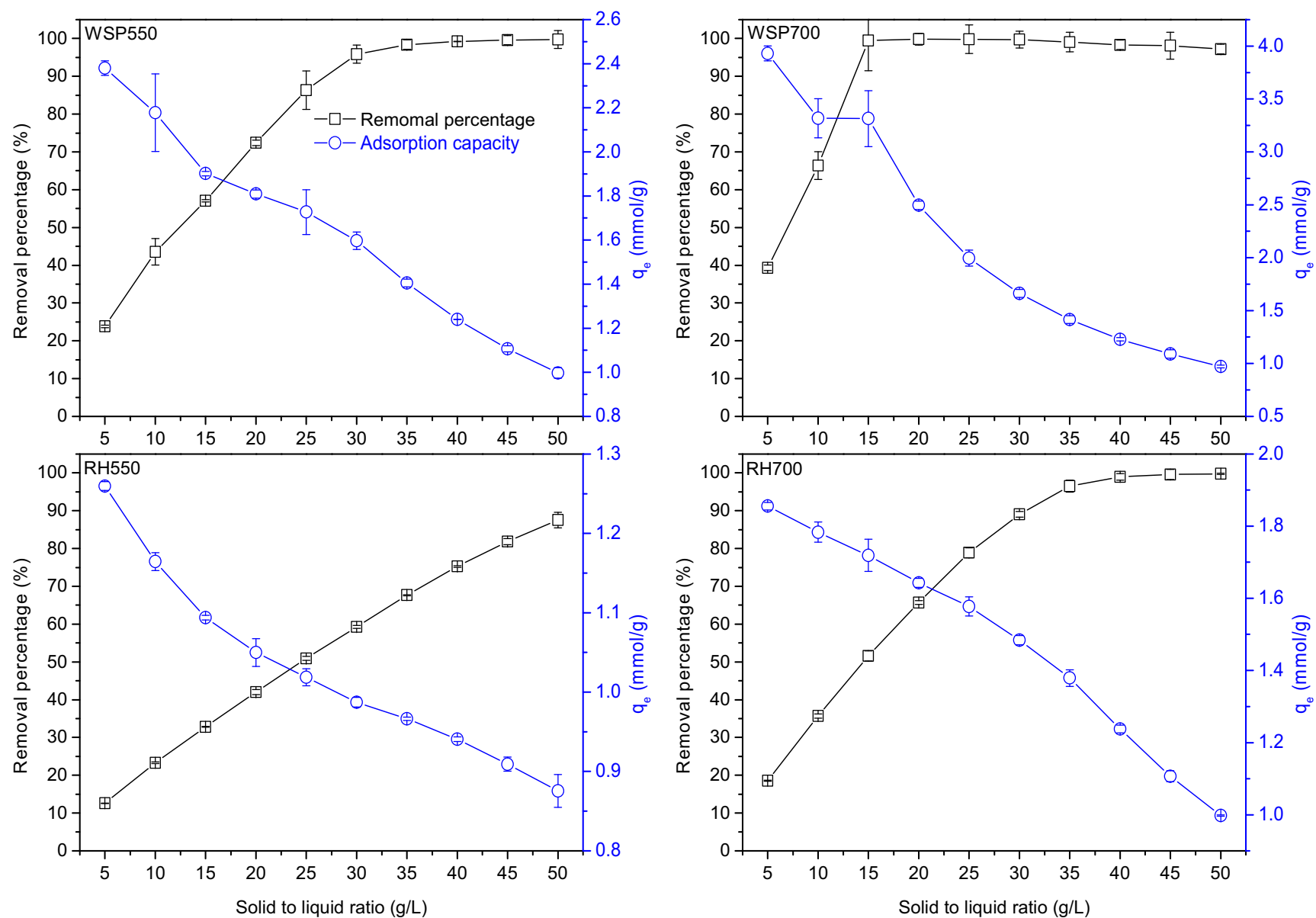

Fig. 4 The influence of solid to liquid ratio on $\mathrm{Ni}^{2+}$ removal percentage and the adsorbed amount of $\mathrm{Ni}^{2+}$ per weight unit of biochar (mmol/g) (initial $\mathrm{Ni}^{2+}$ concentration $5 \mathrm{mM}$ in $20 \mathrm{~mL}$ solution (containing $0.01 \mathrm{M} \mathrm{NaNO}_{3}$ ), reaction temperature $20^{\circ} \mathrm{C}$, initial solution $\mathrm{pH} 5$, contact time $24 \mathrm{~h}$ )

At $\mathrm{pH} 2$, the $\mathrm{Ni}^{2+}$ removal percentages for all biochars are $<10 \%$. They increase as initial $\mathrm{pH}$ increases from 2 to 4 and stays effectively constant (around 39, 25, 20 and 13\% for WSP700, WSP550, RH700 and RH550, respectively) within the $\mathrm{pH}$ range of 4-7. All biochars show either little change, or a slight increase (within 3\%), between $\mathrm{pH}$ values of $7-8$, and exhibit sharp increases between $\mathrm{pH}$ values of 8-9. All biochars reach almost completed removal $(\geq 98 \%)$ at $\mathrm{pH} 9$ and therefore exhibit no significant further change for $\mathrm{pH} 10$.

The $\mathrm{Ni}^{2+}$ removal percentage is closely dependent on the equilibrium $\mathrm{pH}$, in line with the findings of Mohan et al. (2014) and Shen et al. (2015). The equilibrium pH for all biochars increases at low initial $\mathrm{pH}$ values (with the range of $2-3$ or 2-4) and the $\mathrm{Ni}^{2+}$ removal percentages correspondingly increase within this range. The increases in $\mathrm{Ni}^{2+}$ removal at this range are likely due to that the increase of solution $\mathrm{pH}$ enhances the deprotonation process of the functional groups on biochar surface and therefore create more negatively charged sites, thus increasing the adsorption of the cationic heavy metals (Qiu et al. 2008; Mohan et al. 2014). The equilibrium $\mathrm{pH}$ values stay almost constant through the initial $\mathrm{pH}$ range of 4-8; hence, the $\mathrm{Ni}^{2+}$ removal percentage stays nearly constant for all biochars within this range. The sharp increase in the $\mathrm{Ni}^{2+}$ removal between initial $\mathrm{pH}$ values of 8 and 9 is due to electrostatic adsorption of $\mathrm{Ni}^{2+}$ on biochar. At high $\mathrm{pH}$ values, the equilibrium solution $\mathrm{pH}$ exceeded the $\mathrm{pH}_{\mathrm{pzc}}$ of the biochar and hence more negatively charged sites on biochar surface are created, enhancing the electrostatic adsorption $\mathrm{Ni}^{2+}$ on biochar (Yang and Jiang 2014). At pH 9-10, the increasing $\mathrm{pH}$ further enhanced the electrostatic adsorption; simultaneously, the saturation index of $\mathrm{Ni}(\mathrm{OH})_{2}$ increased (Fig. 5) significantly and therefore $\mathrm{Ni}^{2+}$ precipitates with $\mathrm{OH}^{-}$to form Ni $(\mathrm{OH})_{2}$ (Nam et al. 2015; Kadirvelu et al. 2001) which will likely be retained on the biochar surface (Inyang. 2015). It can be found from the MINTEQ analysis (Fig. 5) that the changes in solubility of $\mathrm{Ni}^{2+}$ did not have a significant effect on $\mathrm{Ni}^{2+}$ removal between $\mathrm{pH} 2$ and 9.

The $\mathrm{Ni}^{2+}$ removal percentage at a specific $\mathrm{pH}$ within 2-8 follows the findings from Figs. 3 and 4, that WSP700 has the strongest adsorption capacity towards $\mathrm{Ni}^{2+}$ followed by WSP500, RH700 and RH500. All biochars showed the similar trend of $\mathrm{pH}$ dependence. At high $\mathrm{pH}$ values (9 and 10), the biochars exhibited completed removal of $\mathrm{Ni}^{2+}$ regardless of their feedstocks and production temperatures. Shen et al. 

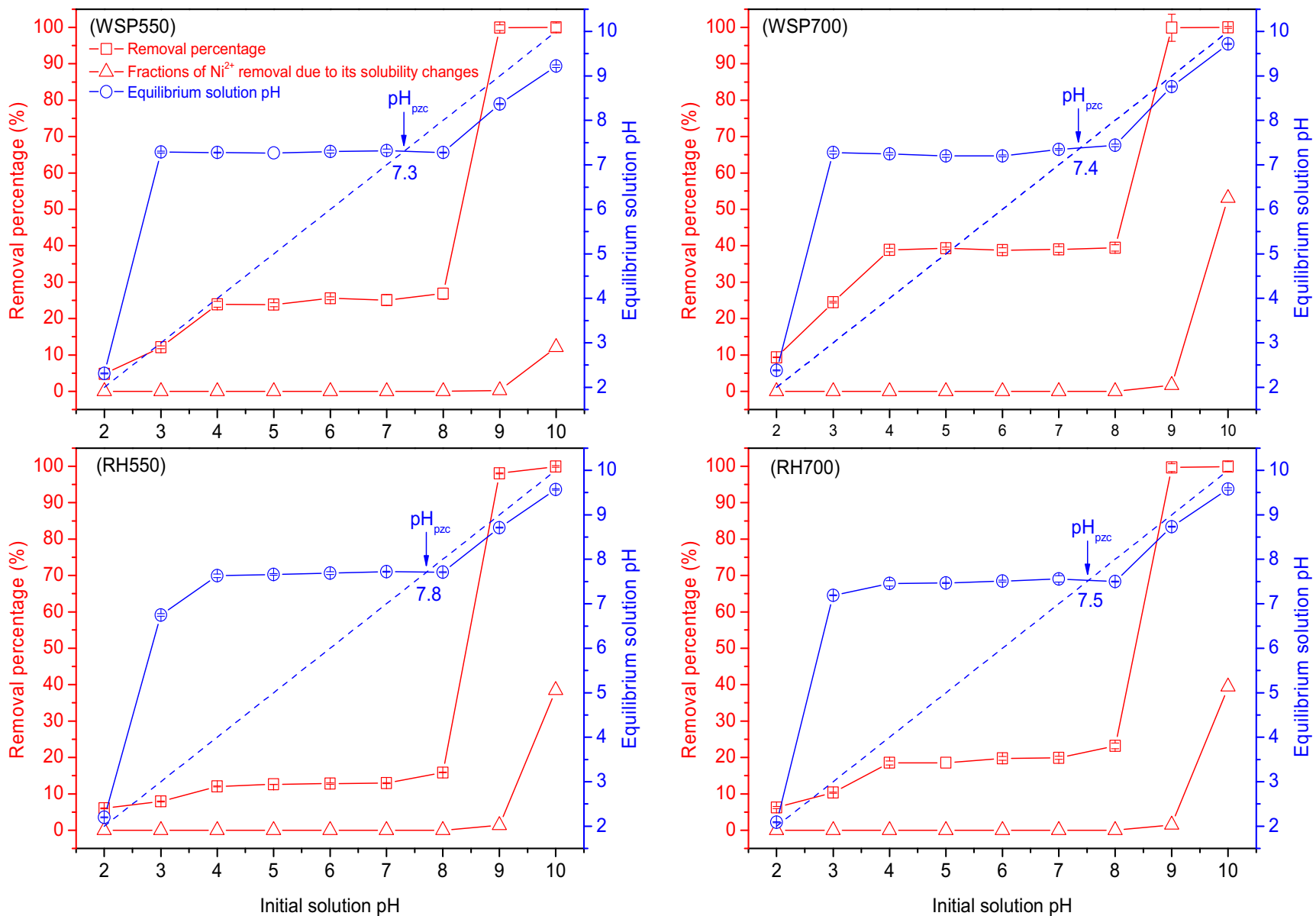

Fig. 5 The influence of initial solution $\mathrm{pH}$ on the $\mathrm{Ni}^{2+}$ removal percentage; the fractions of $\mathrm{Ni}^{2+}$ removal caused by the formation of $\mathrm{Ni}$ $(\mathrm{OH})_{2}$ due to solubility; and the equilibrium solution $\mathrm{pH}$; the dashed line

(2015) observed a completed removal of $\mathrm{Pb}^{2+}$ at initial solution $\mathrm{pH}$ values between 8 and 10. Both Shen et al. (2015) and this study suggest that the adsorption of heavy metals on biochars at high $\mathrm{pH}$ (higher than 8 or 9) is more solution $\mathrm{pH}$ controlled than biochar controlled.

The buffering effect of the biochars within the $\mathrm{pH}$ range of approximately 4-8 suggests their potential resistance to the environmental changes in soil $\mathrm{pH}$ (such as groundwater flow and acid rainfall) and will therefore aid the immobilisation of heavy metals in the long term, although this resistance will be dependent on the site soil constitute, rainfall volume and biochar dosage etc. Similarly, a sharp decrease in adsorption capacity is not observed until very low $\mathrm{pH}$ values (approximately 3-4), which is unlikely to occur in typical soils.

\section{Adsorption equilibrium}

The equilibrium data of $\mathrm{Ni}^{2+}$ are fitted to the Langmuir and Freundlich isotherm models and shown in Fig. 6 and Table 2. The $R^{2}$ values were within $0.741-0.901$ for Langmuir model, which were comparable to those $(0.626-0.889)$ for Freundlich

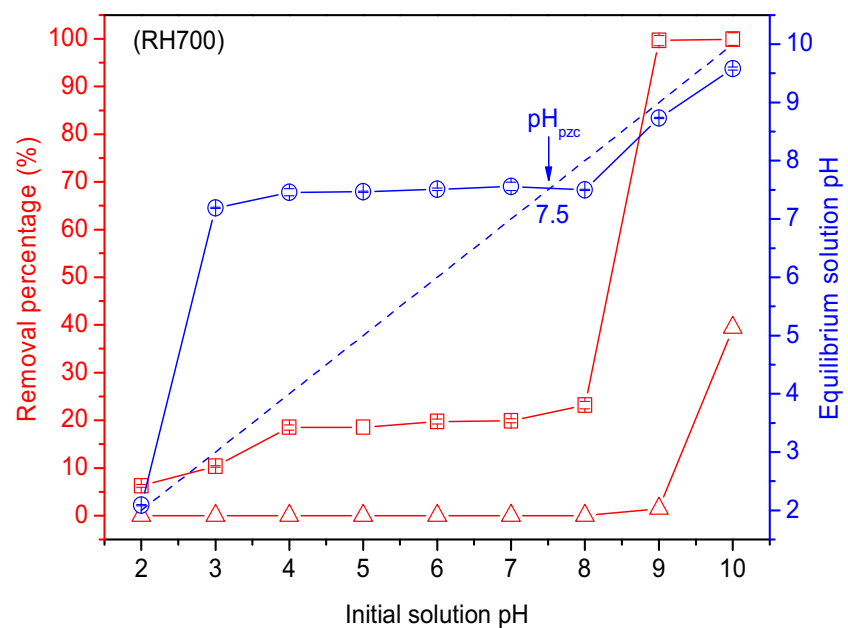

is used to obtain the $\mathrm{pH}_{\mathrm{pzc}}$ (initial $\mathrm{Ni}^{2+}$ concentration $5 \mathrm{mM}, 0.1 \mathrm{~g}$ biochar in $20 \mathrm{~mL}$ solution (containing $0.01 \mathrm{M} \mathrm{NaNO}_{3}$ ), reaction temperature $20{ }^{\circ} \mathrm{C}$, contact time $24 \mathrm{~h}$ )

model. According to the AIC test results, the Freundlich model was 1.465 times more likely to be correct to describe the equilibrium data compared with the Langmuir model, suggesting a heterogeneous adsorption surface for the biochars. The calculated maximum adsorption capacity of the biochars follows the order WSP700 > WSP550 > RH700 > RH550, with the value of $0.427,0.215,0.173,0.117 \mathrm{mmol} / \mathrm{g}$, which is in line with the findings in sections "Kinetics", "Influence of solid to liquid ratio on $\mathrm{Ni2}+$ adsorption" and "Influence of solution $\mathrm{pH}$ on Ni2+ adsorption".

As very limited adsorption characterisations of $\mathrm{Ni}^{2+}$ on biochars have been carried out to date, it is difficult to make relevant comparisons between this study and existing literature. All biochars exhibited higher maximum adsorption capacities of $\mathrm{Ni}^{2+}$ than Salisbury biochar $(0.105 \mathrm{mmol} / \mathrm{g})$ applied on a contaminated site in a previous study (Shen et al. 2016) as well as a more rapid adsorption of $\mathrm{Ni}^{2+}$ (Shen et al. 2015). In addition, these biochars exhibited higher resistances to the changing in environmental $\mathrm{pH}$, which may aid the longterm stability of heavy metal immobilisation in field soil. Therefore, as Salisbury biochar was relatively successful in 


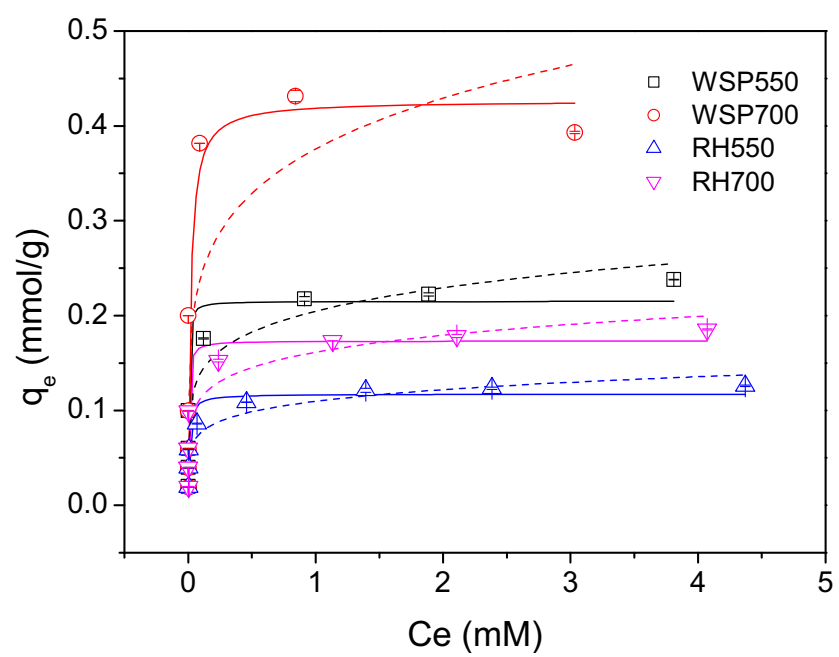

Fig. 6 Adsorption equilibrium of $\mathrm{Ni}^{2+}$ fitted by Langmuir isotherm model (straight lines) and Freundlich model (dash lines) $\left(q_{\mathrm{e}}-\right.$ adsorption capacity at equilibrium, $C_{\mathrm{e}}-\mathrm{Ni}^{2+}$ concentration at equilibrium) $(0.1 \mathrm{~g}$ biochar in $20 \mathrm{~mL}$ solution (containing $0.01 \mathrm{M}$ $\mathrm{NaNO}_{3}$ ), reaction temperature $20^{\circ} \mathrm{C}$, initial solution $\mathrm{pH}$, contact time $24 \mathrm{~h})$

immobilising $\mathrm{Ni}^{2+}$ on this site in a 3-year preliminary study (Shen et al. 2016), these four biochars have the potential to be applied to similar sites.

\section{Discussion}

Influence of biochar physicochemical properties on $\mathrm{Ni}^{2+}$ adsorption

The high $\mathrm{pH}$ dependence of $\mathrm{Ni}^{2+}$ adsorption on biochars suggests that the adsorption is likely controlled by electrostatic adsorption or surface precipitation, as both of them are highly pH dependent (Meena et al. 2008; Inyang et al. 2012). However, other adsorption mechanisms such as cation exchange and surface complexation cannot be excluded at this stage. Physical adsorption can be excluded as it usually lasts longer and is reversible (Inyang et al. 2015), which conflicts with the findings in kinetic and equilibrium studies. (a)

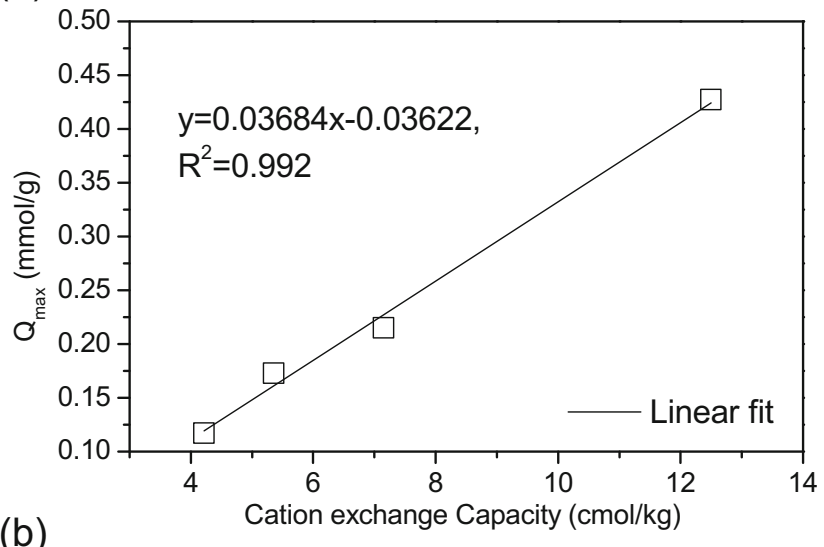

(b)

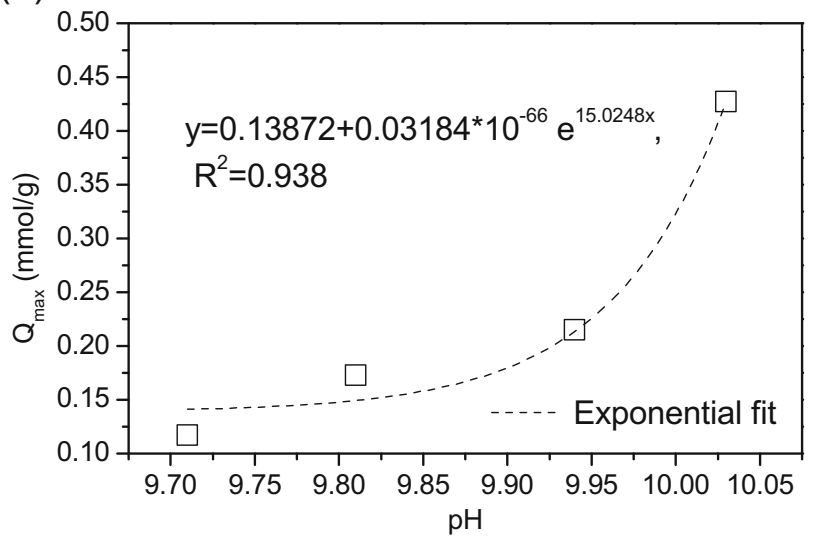

Fig. 7 The relation between maximum adsorption capacity $\left(Q_{\max }\right)$ of $\mathrm{Ni}^{2+}$ and cation exchange capacity (a) and $\mathrm{pH}$ of biochar (b)

In order to further explore the adsorption mechanisms, the relationship between $\mathrm{Ni}^{2+} Q_{\max }$ and the physicochemical properties of the biochars are analysed and shown in Fig. S1 and Fig. 7. No significant relationships between $\mathrm{Ni}^{2+} \mathrm{Q}_{\max }$ and $\mathrm{O}: \mathrm{C}$ value, VM content, surface area or ash content were observed (Fig. S1). The O:C value is highly related to the Ocontaining acidic functional groups and $\mathrm{VM}$ is also a strong indicator of acidic functional groups (e.g. carboxyl and phenol) (Uchimiya et al. 2011); therefore, the insignificant relationships between $Q_{\max }$ and VM content and O:C value
Table 2 Parameters and regression coefficient of the equilibrium data fitted by linear Langmuir and Freundlich isotherm models

\begin{tabular}{|c|c|c|c|c|c|c|}
\hline \multirow[t]{2}{*}{ Biochar } & \multicolumn{3}{|l|}{ Langmuir } & \multicolumn{3}{|c|}{ Freundlich } \\
\hline & $Q_{\max }(\mathrm{mmol} / \mathrm{g})$ & $b(\mathrm{~L} / \mathrm{mmol})$ & $R^{2}$ & $K$ & $1 / n$ & $R^{2}$ \\
\hline WSP550 & 0.215 & 346.329 & 0.875 & 0.204 & 0.164 & 0.889 \\
\hline WSP700 & 0.427 & 52.157 & 0.741 & 0.376 & 0.192 & 0.626 \\
\hline RH550 & 0.117 & 121.930 & 0.901 & 0.110 & 0.153 & 0.876 \\
\hline RH700 & 0.173 & 247.234 & 0.838 & 0.161 & 0.152 & 0.853 \\
\hline AIC value & \multicolumn{3}{|l|}{-48.778} & \multicolumn{3}{|c|}{-48.014} \\
\hline Akaike weight & \multirow{2}{*}{\multicolumn{3}{|c|}{0.594}} & \multicolumn{3}{|l|}{0.406} \\
\hline AIC conclusion & & & & \multicolumn{3}{|c|}{1.465 times more likely to be correct } \\
\hline
\end{tabular}


suggest that the acidic functional groups and associated surface complexation (Inyang et al. 2015) may not control the $\mathrm{Ni}^{2+}$ adsorption on the biochars. The insignificant relationship between $Q_{\text {max }}$ and surface area suggests that physical adsorption is not the predominant adsorption mechanism (Inyang et al. 2015), which is in line with the findings from kinetic study and equilibrium studies. Ash content was also not observed to have a close correlation with $Q_{\text {max }}$.

In contrast, a significant positive linear relationship $\left(R^{2}=0.992\right)$ between $\mathrm{Ni}^{2+} Q_{\max }$ and CEC was observed (Fig. 6a), indicating that CEC may play an important role in $\mathrm{Ni}^{2+}$ adsorption. However, CEC cannot be the only mechanism controlling $\mathrm{Ni}^{2+}$ adsorption on the biochars. If the adsorbed $\mathrm{Ni}^{2+}$ through cation exchange reaches the maximum, this part will account for 33, 29, 36 and $31 \%$ of the $Q_{\text {max }}$ of SWP550, SWP700, RH550 and RH700, respectively. Therefore, there must be other mechanisms controlling $\mathrm{Ni}^{2+}$ adsorption on the biochars together with CEC. It can be found from this study that CEC becomes a good indicator for the $\mathrm{Ni}^{2+} Q_{\text {max }}$ of biochar, and biochar with high CEC may have a high adsorption capacity of $\mathrm{Ni}^{2+}$.

$\mathrm{Ni}^{2+} Q_{\text {max }}$ exhibited an approximately exponential relationship $\left(R^{2}=0.938\right)$ with the $\mathrm{pH}$ of biochar (Fig. 6b). The alkalinity of biochar is due to the formation of alkaline minerals (e.g. $\mathrm{K}_{2} \mathrm{O}, \mathrm{K}_{2} \mathrm{CO}_{3}$ ) during production (Dodson 2011; Wang et al. 2014). A higher $\mathrm{pH}$ of biochar can result in a more alkaline environment on its surface which will favour the precipitation of $\mathrm{Ni}^{2+}$ on it; therefore, surface precipitation may be a mechanism controlling the adsorption of $\mathrm{Ni}^{2+}$ on the biochars. In addition, the formation of aromatic structure is accompanied with the formation of alkaline minerals during biochar production (Dodson 2011). A higher $\mathrm{pH}$ of biochar with higher alkaline mineral content also suggests a more active aromatic structure, which will aid the electrostatic adsorption (cation- $\pi$ interaction) (Keiluweit et al. 2010). Therefore, this exponential relationship between $\mathrm{Ni}^{2+} Q_{\max }$ and biochar $\mathrm{pH}$ suggests that surface precipitation and electrostatic adsorption may be two of the mechanisms controlling $\mathrm{Ni}^{2+}$ adsorption on the biochars.

It is of note that the alkaline minerals in biochar offers potential exchangeable cations (e.g. $\mathrm{Na}^{+}$and $\mathrm{K}^{+}$), which has been confirmed by the CEC results (Table S1). Therefore, the CEC is highly related to the content of alkaline minerals in biochar. The good indication of CEC and $\mathrm{pH}$ for $\mathrm{Ni}^{2+} \mathrm{Q}_{\max }$ is likely both due to the alkaline minerals in the biochars.

\section{The influence of feedstock type and production temperature on $\mathrm{Ni}^{2+}$ adsorption}

As indicated across the paper, the adsorption capacity of $\mathrm{Ni}^{2+}$ on the biochar is highly related to its feedstock type and production temperature. WSP-derived biochar exhibited higher adsorption capacities than RH. Wheat straw and rice husk both mainly consist of cellulose, hemicellulose and lignin (Table S2). Wheat straw commonly contains more cellulose than rice husk ( $45.0 \%$ versus $34.5 \%$ ) (Table S2), which can be easily decomposed under heating (Keiluweit et al. 2010). The decomposition process of wheat straw is shown in Dodson (2011). The carboxylate on the edge of the aromatic hydrocarbon will be decomposed and release alkaline cations (e.g. $\mathrm{K}^{+}$) to form alkaline minerals (e.g. $\mathrm{K}_{2} \mathrm{O}, \mathrm{K}_{2} \mathrm{CO}_{3}$ ) and simultaneously increase the aromaticity during production. Therefore, more cellulose content may result in more alkaline minerals and higher aromaticity and consequently higher adsorption capacities for WSP derived biochar. The higher $\mathrm{pH}$, CEC and K contents (Table 1) for WSP-derived biochars also support this proposed mechanism.

RH-derived biochars contain more $\mathrm{SiO}_{2}$ (as indicated by FT-IR spectra) and ash contents (Table 1) than WSP. Ash can block the pores on the biochar surface (Upamali et al. 2016) and therefore lower its adsorption capacity. This may also have contributed to the lower adsorption of $\mathrm{Ni}^{2+}$ for $\mathrm{RH}$ derived biochars.

For the same feedstock, a higher production temperature will result in the formation of more alkaline minerals (Dodson 2011) (higher $\mathrm{pH}$ ) which will aid surface precipitation and cation exchange, and more active aromatic structure which will aid electrostatic adsorption (Keiluweit et al. 2010). This explains why biochars produced at higher temperature exhibited higher $\mathrm{Ni}^{2+}$ adsorption capacity for the same feedstock.

In addition to biochar type, the adsorption of heavy metals on biochar depends on the properties of heavy metals such as hydrated radius, hydrolysis constant, electronegativity and relative binding strength (Sdiri et al. 2012; Sdiri et al. 2016). It is of note that this study only investigated the adsorption of $\mathrm{Ni}^{2+}$ on the biochars. Therefore, the adsorption of other heavy metals on the biochars may vary from $\mathrm{Ni}^{2+}$, which needs to be investigated in the future.

\section{Conclusions}

In this study, the adsorption characteristics of $\mathrm{Ni}^{2+}$ on four standard biochars were investigated. The kinetic results show that the adsorption of $\mathrm{Ni}^{2+}$ on the biochars reached an equilibrium within $5 \mathrm{~min}$. Greater solid to liquid ratios resulted in an increase of $\mathrm{Ni}^{2+}$ removal percentage but a decrease in the adsorbed amount of $\mathrm{Ni}^{2+}$ per weight unit of biochar. The $\mathrm{Ni}^{2+}$ removal percentage increased with the increasing of initial solution $\mathrm{pH}$ values at the range of $2-4$, was relatively constantly at the $\mathrm{pH}$ range of 4-8, and significantly increased to $\geq 98 \%$ at $\mathrm{pH} 9$ and stayed constantly at the $\mathrm{pH}$ range of 9-10. The Freundlich model was 1.465 times more likely to be correct to describe the equilibrium data compared with the Langmuir model according to the AIC test. The equilibrium 
study shows that WSP700 has the highest adsorption capacity for $\mathrm{Ni}^{2+}$, followed by WSP550, RH700 and RH550. The calculated maximum adsorption capacities of $\mathrm{Ni}^{2+}$ on the biochars are higher than that of Salisbury biochar which was applied to and performed well on a real contaminated site. Therefore, considering the more rapid reaction with $\mathrm{Ni}^{2+}$, higher resistance to changing $\mathrm{pH}$ and higher adsorption capacities of $\mathrm{Ni}^{2+}$ compared with Salisbury biochar, the standard biochars have the potential to be applied to $\mathrm{Ni}^{2+}$ contaminated sites.

The adsorption mechanism analysis suggests that biochar adsorbs $\mathrm{Ni}^{2+}$ predominantly through cation exchange, electrostatic adsorption and surface precipitation. Both $\mathrm{pH}$ and $\mathrm{CEC}$ of biochar can be a good indicator of its maximum adsorption capacity for $\mathrm{Ni}^{2+}$ through a positively linear and exponential relation, respectively. The differences between adsorption capacities of the biochars originate from the differences between the feedstock type and production temperature, which determine the alkaline mineral contents and associated $\mathrm{pH}$ and CEC, ash contents and aromatization degrees of the biochars.

This study also shows that a carefully controlled standardised production procedure makes it reliable to compare the adsorption capacities between different biochars and investigate the mechanisms involved. Analytical methods such as scanning electron microscopy with energydispersive X-ray analysis, X-ray diffusion analysis, X-ray photoelectron spectroscopy surface analysis, thermogravimetric analysis and sequential analysis are encouraged to be conducted for further investigation of the adsorption mechanisms. Biochars from various feedstocks are suggested to be produced according to the standard procedure of the UKBRC so that relevant comparisons can be made to identify the suitable biochars for specific contaminated sites and explore their adsorption mechanisms for heavy metals.

\begin{abstract}
Acknowledgements The standard biochars were obtained from the UK Biochar Research Centre (UKBRC) at the University of Edinburgh. The authors would like to thank Dr. Ondrej Masek from the UKBRC for his kind help in preparing and delivering the biochar samples. Special thanks also go to Dr. Zhen Li from the College of Resources and Environmental Sciences, Nanjing Agricultural University, China, who conducted the SEM tests for the biochars used in this study.
\end{abstract}

Open Access This article is distributed under the terms of the Creative Commons Attribution 4.0 International License (http:// creativecommons.org/licenses/by/4.0/), which permits unrestricted use, distribution, and reproduction in any medium, provided you give appropriate credit to the original author(s) and the source, provide a link to the Creative Commons license, and indicate if changes were made.

\section{References}

Alemdar A, Sain M (2008) Isolation and characterization of nanofibers from agricultural residues-wheat straw and soy hulls. Bioresour Technol 99:1664-1671
Armesto L, Bahillo A, Veijonen K et al (2002) Combustion behaviour of rice husk in a bubbling fluidised bed. Biomass Bioenergy 23:171179. doi:10.1016/S0961-9534(02)00046-6

Beesley L, Moreno-Jiménez E, Gomez-Eyles JL et al (2011) A review of biochars' potential role in the remediation, revegetation and restoration of contaminated soils. Environ Pollut 159:3269-3282. doi:10. 1016/j.envpol.2011.07.023

Dodson J (2011) Wheat straw ash and its use as a silica source.

Foo KY, Hameed BH (2010) Insights into the modeling of adsorption isotherm systems. Chem Eng J 156:2-10. doi:10.1016/j.cej.2009. 09.013

Gao H, Sun Y, Zhou J et al (2013) Mussel-inspired synthesis of polydopamine-functionalized graphene hydrogel as reusable adsorbents for water purification. ACS Appl Mater Interfaces 5:425-432. doi:10.1021/am302500v

Gillman G, Sumpter E (1986) Modification to the compulsive exchange method for measuring exchange characteristics of soils. Aust J Soil Res 24:61. doi:10.1071/SR9860061

Inyang M, Gao B, Yao Y et al (2012) Removal of heavy metals from aqueous solution by biochars derived from anaerobically digested biomass. Bioresour Technol 110:50-56. doi:10.1016/j.biortech. 2012.01.072

Inyang MI, Gao B, Yao Y et al (2015) A review of biochar as a low-cost adsorbent for aqueous heavy metal removal. Crit Rev Environ Sci Technol:00-00. doi:10.1080/10643389.2015.1096880

Kadirvelu K, Thamaraiselvi K, Namasivayam C (2001) Adsorption of nickel (II) from aqueous solution onto activated carbon prepared from coirpith. Sep Purif Technol 24:497-505. doi:10.1016/S13835866(01)00149-6

Keiluweit M, Nico PS, Johnson M, Kleber M (2010) Dynamic molecular structure of plant biomass-derived black carbon (biochar). Environ Sci Technol 44:1247-1253. doi: 10.1021/es9031419

Lal R (2005) World crop residues production and implications of its use as a biofuel. Environ Int 31:575-584. doi:10.1016/j.envint.2004.09. 005

Lehmann J (2007) Bio-energy in the black. Front Ecol Environ preprint 1. doi: $10.1890 / 060133$

Liu P, Liu WJ, Jiang H et al (2012a) Modification of bio-char derived from fast pyrolysis of biomass and its application in removal of tetracycline from aqueous solution. Bioresour Technol 121:235240. doi:10.1016/j.biortech.2012.06.085

Liu Y, Zhao X, Li J et al (2012b) Characterization of bio-char from pyrolysis of wheat straw and its evaluation on methylene blue adsorption. Desalin Water Treat 46:115-123. doi:10.1080/19443994. 2012.677408

Manyà JJ (2012) Pyrolysis for biochar purposes: a review to establish current knowledge gaps and research needs. Environ Sci Technol 46:7939-7954. doi:10.1021/es301029g

Meena AK, Kadirvelu K, Mishra GK et al (2008) Adsorptive removal of heavy metals from aqueous solution by treated sawdust (Acacia arabica). J Hazard Mater 150:604-611. doi:10.1016/j.jhazmat. 2007.05.030

Meng J, Feng X, Dai Z et al (2014) Adsorption characteristics of Cu (II) from aqueous solution onto biochar derived from swine manure. Environ Sci Pollut Res Int 21:7035-7046. doi:10.1007/s11356014-2627-z

Mohan D, Kumar H, Sarswat A et al (2014) Cadmium and lead remediation using magnetic oak wood and oak bark fast pyrolysis biochars. Chem Eng J 236:513-528. doi:10.1016/j.cej.2013.09.057

Nam K-M, Kim H-J, Kang D-H et al (2015) Ammonia-free coprecipitation synthesis of a $\mathrm{Ni}-\mathrm{Co}-\mathrm{Mn}$ hydroxide precursor for high-performance battery cathode materials. Green Chem 17:11271135. doi:10.1039/C4GC01898B

Qiu Y, Cheng H, Xu C, Sheng GD (2008) Surface characteristics of cropresidue-derived black carbon and lead (II) adsorption. Water Res 42: 567-574. doi:10.1016/j.watres.2007.07.051 
QU J, Zheng J, Zheng J et al (2012) Effects of wheat-straw-based biochar on yield of rice and nitrogen use efficiency of late rice $[\mathrm{J}]$. J Ecol Rural Environ 3:12

Rees F, Simonnot MO, Morel JL (2014) Short-term effects of biochar on soil heavy metal mobility are controlled by intra-particle diffusion and soil pH increase. Eur J Soil Sci 65:149-161. doi:10.1111/ejss. 12107

Ronsse F, van Hecke S, Dickinson D, Prins W (2013) Production and characterization of slow pyrolysis biochar: influence of feedstock type and pyrolysis conditions. GCB Bioenergy 5:104-115. doi:10. $1111 / \mathrm{gcbb} .12018$

Saleh ME, El-Refaey AA, Mahmoud AH (2016) Effectiveness of sunflower seed husk biochar for removing copper ions from wastewater: a comparative study. Soil water res 11:53-63. doi:10.17221/274/ 2014-SWR

Sdiri A, Higashi T, Chaabouni R, Jamoussi F (2012) Competitive removal of heavy metals from aqueous solutions by montmorillonitic and calcareous clays. Water Air Soil Pollut 223:1191-1204. doi:10. 1007/s11270-011-0937-z

Sdiri A, Khairy M, Bouaziz S, El-Safty S (2016) A natural clayey adsorbent for selective removal of lead from aqueous solutions. Appl Clay Sci 126:89-97. doi:10.1016/j.clay.2016.03.003

Shen Z, Jin F, Wang F et al (2015) Sorption of lead by Salisbury biochar produced from British broadleaf hardwood. Bioresour Technol 193: 553-556. doi:10.1016/j.biortech.2015.06.111

Shen Z, Som AM, Wang F et al (2016) Long-term impact of biochar on the immobilisation of nickel (II) and zinc (II) and the revegetation of a contaminated site. Sci Total Environ 542:771-776. doi:10.1016/j. scitotenv.2015.10.057

Sizmur T, Quilliam R, Puga AP, et al (2015) Application of Biochar for soil remediation. 1-40. doi: 10.2136/sssaspecpub63.2014.0046.5
Sohi SP (2012) Carbon storage with benefits. Science 338:1034-1035. doi:10.1126/science. 1225987

Tran HN, You S-J, Chao H-P (2016) Effect of pyrolysis temperatures and times on the adsorption of cadmium onto orange peel derived biochar. Waste Manag Res 34:129-138. doi:10.1177/ $0734242 X 15615698$

Uchimiya M, Wartelle LH, Klasson KT et al (2011) Influence of pyrolysis temperature on biochar property and function as a heavy metal sorbent in soil. J Agric Food Chem 59:2501-2510. doi:10.1021/ jf104206c

UK Biochar Research Centre (2016). http://www.biochar.ac.uk

Upamali A, Chen SS, Tsang DCW et al (2016) Chemosphere engineered/designer biochar for contaminant removal/ immobilization from soil and water: potential and implication of biochar modification. Chemosphere 148:276-291. doi:10. 1016/j.chemosphere.2016.01.043

Wang Z, Liu G, Zheng $\mathrm{H}$ et al (2014) Investigating the mechanisms of biochar's removal of lead from solution. Bioresour Technol. doi:10. 1016/j.biortech.2014.11.077

Xin S, Yang H, Chen Y et al (2015) Chemical structure evolution of char during the pyrolysis of cellulose. J Anal Appl Pyrolysis. doi:10. 1016/j.jaap.2015.09.002

Yang GX, Jiang H (2014) Amino modification of biochar for enhanced adsorption of copper ions from synthetic wastewater. Water Res 48 : 396-405. doi:10.1016/j.watres.2013.09.050

Zhang X, Wang H, He L et al (2013) Using biochar for remediation of soils contaminated with heavy metals and organic pollutants. Environ Sci Pollut Res Int 20:8472-8483. doi:10.1007/s11356013-1659-0 